\title{
e-interview
}

\section{Professor Sheila Hollins}

Sheila Hollins is President of the College, Professor of Psychiatry of Learning Disability at the University of London and Consultant Psychiatrist in Learning Disability in South West London \& St George's Mental Health Trust. She trained at Queen Mary's Hospital, Roehampton, Westminster Children's Hospital and St George's Hospital. Her research interests include health inequalities, end-of-life care and clinical outcomes following bereavement and abuse.

If you were not a psychiatrist, what would you do?

Be a cook, an anthropologist or a photographer!

When you are on holiday and people ask 'what do you do', what do you tell them?

That I am a psychiatrist.

Is there any aspect of work that induces procrastination?

Too much paperwork!

Do you have a mentor?

Yes and I have had different mentors at different stages of my career - not always another doctor.

Why do you enjoy research?

I enjoy testing out my assumptions and developing scientific support to validate my clinical experience. I also love teaching and sharing findings from research and practice with students and professionals, as well as trying to make these accessible to people with learning disabilities and those who have mental illness and their families and carers.

\section{Should wards be single or mixed} gender?

It depends on the nature of the service. I think acute wards should be single gender, but patients in many therapeutic and longer-stay wards will benefit from mixing with both men and women, providing the services are gender sensitive and that issues of safety are properly addressed.

\section{Is psychiatry a thankless task?}

If you mean do patients and families say thank you, then I would say thanks are offered less frequently than following surgery. Psychiatrists, however, are usually reflective by nature and the personal rewards of knowing that we have helped individuals and their families and carers are often enough. Thanks don't have to be articulated for us to gain satisfaction from a job well done.

What has been the highlight of your career?

There have been many highlights. One was being elected President - what a vote of confidence and such a boost to my

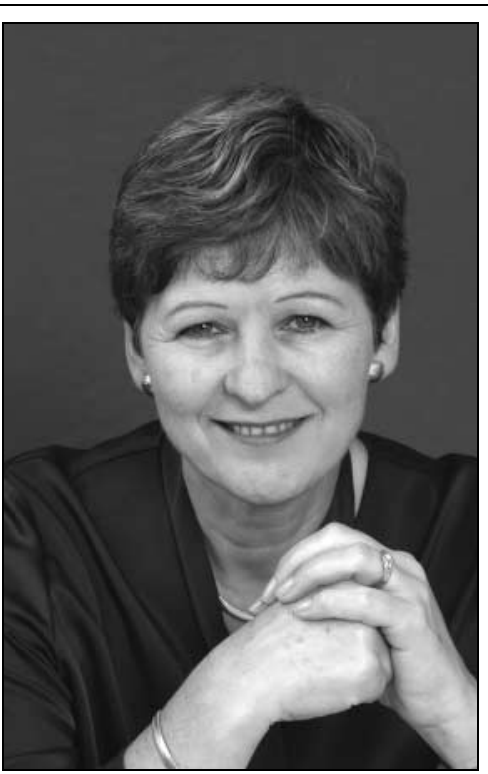

aspirations for psychiatry! Others have been related to magical moments with patients when a significant insight or improvement occurs after a seemingly impossible delay.

... and the lowlight?

Being bullied by a senior colleague.

Have you ever surprised yourself? Constantly.

\section{.. or been disappointed?}

Yes - when a grant application is turned down, especially if I think the referees have been poorly informed about my client group.

How competitive are you?

Probably more than I'm prepared to admit!

What is your greatest ambition?

They change all the time.

What values do you think should be enhanced in psychiatry?

Humility and empathy.

Do you think the MRCPsych exam should be phased out?

No! Despite the limitations of formal assessments, there is no other method of testing all the competencies trainees need to develop. Workplace-based assessments will gradually replace some aspects of assessment, but for the foreseeable future I expect us to have an exam.

\section{Why don't medical students aspire} to be psychiatrists?

One reason may be that medical schools have set entrance requirements that attract students who want to be doctors - not psychiatrists. The entry requirements for psychiatry might more usefully include psychology, English, sociology, theology or philosophy, in addition to some medically relevant science subject. Another reason might be the negative attitudes of other medics, made worse because there aren't enough psychiatrists working in acute hospitals and in primary care to change their attitudes. We need a major expansion in liaison psychiatry to raise awareness of the potential of psychiatry to improve health and well-being

\section{Psychotherapy or psychobabble?}

Psychobabble is such a misunderstanding of what therapy is about! My best therapeutic modality is psychodynamic and, incidentally, I think personality and personal aptitude do influence how good each of us is in a particular therapeutic modality. Emotional intelligence and awareness on the part of both therapist and patient is central to psychological therapies, and far more important than the talking implied by the pejorative use of the word 'babble'.

Is there an argument for psychiatrists having individual psychotherapy? Yes. I think we benefit from experiencing the treatments we offer to our patients. More than that though is the possibility that by facing up to our own struggles, we will be more open to understanding those of our patients. I had therapy myself as a trainee and valued it enormously.

What is your view of the relationship between psychiatry and the drug industry?

That we are rather naive in believing what they tell us - we need to develop critical psychiatry to recognise what is now emerging about unpublished trials. I think we should stop accepting 'sponsorship' and cal it advertising instead. After all that is what it is.

\section{Where is psychiatry going?}

think, as psychiatrists, that we should be explicit about our expertise as physicians but take care to practise holistically, thus also embracing the psychological, social and spiritual aspects of mental disorder, and bringing our humanity into our relationships with our patients and their carers.

What single area of psychiatric practice is most in need of development?

Liaison psychiatry because we need to develop the awareness in other doctors of the mental health needs of people presenting with and recovering from physical illness, and the need to ensure equal access to treatment for physical ailments for people with learning disabilities and/or severe mental illness.

\section{What is the most promising} opportunity facing the profession? To be recognised as core to medicine and ahead of the game with our broad base, excellent relationships with users and carers, 
and our established place in the multidisciplinary provision of healthcare in so many different settings, including the community.

\section{What is the greatest threat?}

That we fail to provide appropriate leadership in mental health services. This is why the College has appointed a Vice-President, Dr Peter Kennedy, with responsibility for developing the role of medical managers.

\section{What conflict of interest do you} encounter most often?

Is it a conflict of interest to be a carer as well as a psychiatrist? If so then it would be this. However, I see being a carer as an inevitable role that we will all play at some point in our lives, although some seem reluctant to acknowledge personal experience as relevant in their own development.
What single change to mental health legislation would you like to see?

A recognition that mental capacity legislation could protect most of our patients' interests without burdensome additional legislation which restricts individual human rights.

Lucy Watkin and Dominic Fannon 